\title{
Learning from errors
}

\section{Miliary tuberculosis in a young Caucasian adult}

\author{
Shahideh Safavi, ${ }^{1}$ Benjamin Colaluca, ${ }^{2}$ Kumuthan Sriskandarajah ${ }^{3}$ \\ ${ }^{1}$ St George's NHS Trust, London, UK \\ ${ }^{2}$ Department of General Medicine, East Surrey Hospital, Surrey, UK \\ ${ }^{3}$ Department of General Surgery, East Surrey Hospital, Surrey, UK \\ Correspondence to Shahideh Safavi, shsafavi@doctors.org.uk
}

\begin{abstract}
Summary
A young Caucasian adult presented to the Accident and Emergency department with small bowel obstruction, which necessitated an exploratory laparotomy. Multiple firm nodules were found with biopsies leading to a diagnosis of peritoneal tuberculosis (TB). Retrospectively, the patient was noted to have classical radiological pulmonary TB findings on a chest radiograph 3 months previously, and 2 weeks later had developed bony infiltration, paravertebral abscesses and likely TB skin lesions.

This case illustrates an unusual presentation in a patient with minimal risk factors yet widespread extra-pulmonary disease. It also highlights the importance of attentive reviewing of $x$-rays.
\end{abstract}

\section{BACKGROUND}

Tuberculosis (TB) is a major public health problem globally and, although WHO reports a reduction in overall incidence rate of TB internationally, the prevalence as well as the number of deaths remains very high. More importantly, the emergence of multi-drug resistant $\mathrm{TB}$ and the interaction between TB and HIV present challenges to global control. ${ }^{1}$

In the UK, although the incidence rate of TB is stabilising with a rate of 13.8 per 100000 population reported in 2007, the proportion of cases with extra-pulmonary TB continue to increase having been found to be at $44 \%$ in 2007 . In the UK, $92 \%$ of cases were reported in England with London accounting for $39 \%$. However, $79 \%$ of cases were born outside UK and predominantly in those born in South Asia and sub-Saharan Africa. ${ }^{2}$

This is the case of a young Caucasian adult who presented with peritonism and was found to have miliary TB. This patient had none of the usual TB risk factors yet, in retrospect, had classical radiological findings and ultimately florid systemic disease. To an extent, this could have been averted.

The hospital management of this case is also interesting and yields important learning points:

- It illustrates how 'risk free' patients can develop the disease.

- It highlights the symptoms, signs and extra-pulmonary manifestations of TB infection.

- Medical respiratory diagnosis is not the only way to diagnose TB.

And crucially for the junior doctor:

- It identifies that once investigations have been requested they need to be followed up and acted upon.

\section{CASE PRESENTATION}

A young Caucasian adult presented to the Accident and Emergency department with a 3-months history of reduced appetite and weight loss of $5 \mathrm{~kg}$, 1-week history of severe colicky abdominal pain as well as a 2-day history of vomit- ing and constipation. There was no medical or surgical history of note.

On examination, the patient was haemodynamically stable with reduced air entry in left lung base but respiratory rate of 16 and oxygen saturation $98 \%$ on air. Abdominal examination showed a distended abdomen with rebound tenderness in right upper quadrant and positive Murphy's sign with normal bowel sounds. At this stage, differential diagnoses of cholecystitis and small bowel obstruction were made. The patient was admitted under the general surgeons and started on intravenous metronidazole and cefuroxime with analgesics and anti-emetics.

\section{INVESTIGATIONS}

The blood results revealed slightly raised inflammatory markers with white blood cell $11.8 \times 10^{9} / 1$, neutrophil $7.7 \times 10^{9} / 1$ and $C$ reactive protein (CRP) $48 \mathrm{mg} / \mathrm{l}$. The abdominal $x$-ray showed faecal loading. As the patient did not respond to analgesics and developed worsening abdominal distension over the next $48 \mathrm{~h}$, an abdominal ultrasound was performed, which showed very marked fatty liver infiltrations, multiple gallstones, free fluid in the abdomen with an unspecific abnormality of the left psoas muscle, and the possibility of perforated appendicitis was made.

The patient was taken to theatre for explorative laparoscopy, which had to be converted to laparotomy as many adhesions and multiple firm nodules were found within the peritoneal cavity.

\section{DIFFERENTIAL DIAGNOSIS}

At this stage, the differential diagnosis of metastatic ovarian carcinoma, carcinoid tumour and military TB were made.

The next day, the patient reported cough, productive of green sputum, shortness of breath and palpitation. On examination, the patient had become pyrexial at $38.9^{\circ} \mathrm{C}$, blood pressure of $85 / 58 \mathrm{mmHg}$, with heart rate $130 \mathrm{bpm}$. Respiratory examination revealed oxygen saturation of 


\section{BMJ Case Reports}

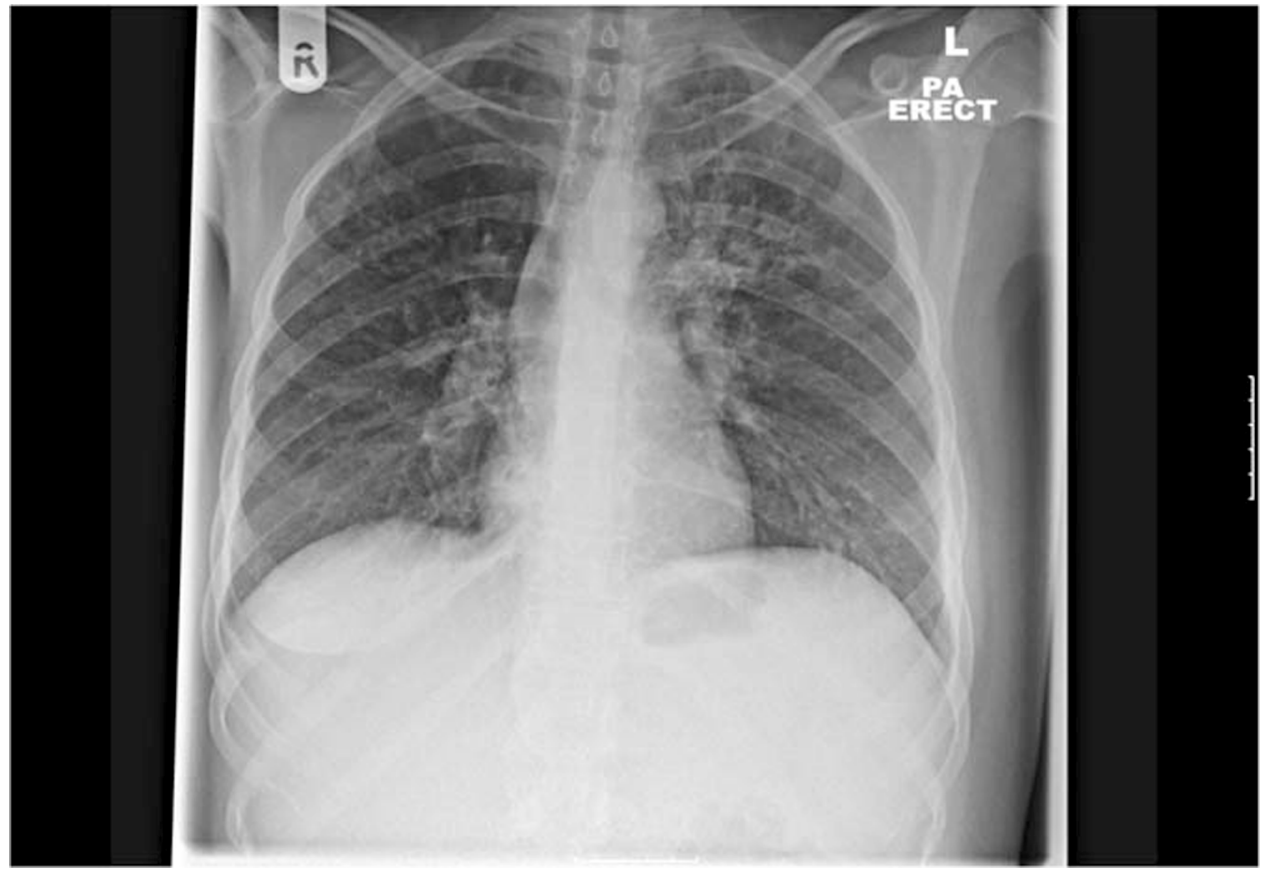

Figure 1 Chest x-ray showing streaky consolidation extending into the left upper lobe as well as the left lower lobe with multiple cavitating lesions highly suggestive of pulmonary tuberculosis.

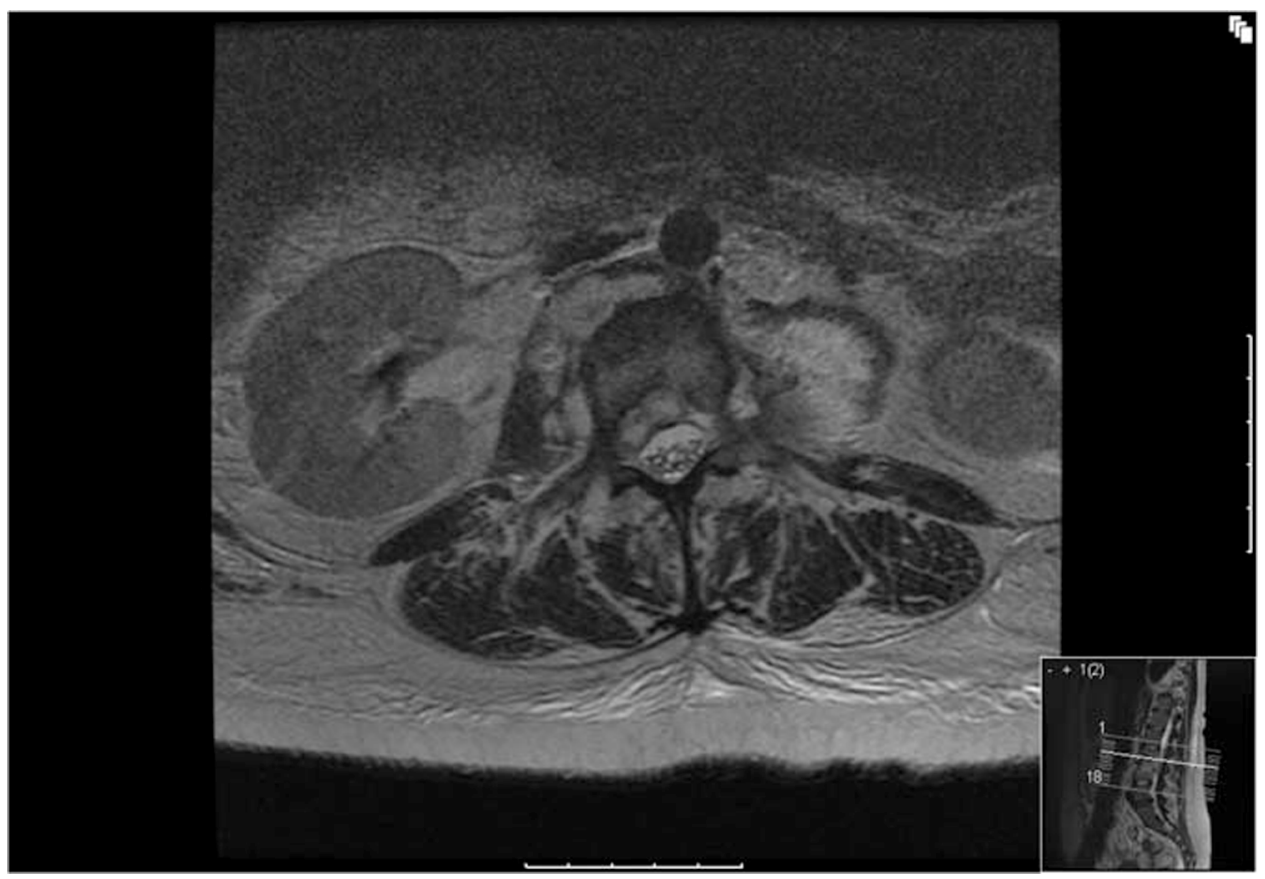

Figure 2 MRI lumbar spine showing a discitis at L3/4 with an epidural abscess compressing the thecal sac and bilateral paraveterbral abscesses.

$92 \%$ on air with tachypnoea of 32 breaths per minute and with reduced air entry in right lung base and left mid-zone.

The blood results showed a marked rise in inflammatory markers with white blood cell $21.1 \times 10^{9} / 1$, neutrophil $17.9 \times 10^{9} / 1$ and CRP $241 \mathrm{mg} / \mathrm{l}$. Severe hospital acquired pneumonia was suspected. Antibiotics were switched in favour of intravenous tazocin and teicoplanin following a discussion with a microbiologist who raised the possibility of methicillin-resistant Staphylococcus aureus (MRSA) pneumonia. 
The biopsy results became available 2 days later and showed caseous granulomatous inflammation suggestive of mycobacterial infection. TB culture showed acid-fast bacilli (AFB).

The patient's previous chest $\mathrm{X}$-rays were reviewed by the radiologist who pointed out that a chest x-ray (figure 1) taken 3 months previously had been reported as showing streaky consolidation extending into the left upper lobe, as well as left lower lobe with multiple cavitating lesions, and a possibility of TB had been raised on the report.

\section{TREATMENT}

Subsequently, the patient was transferred to a single room and started on a combination treatment of rifampicin, isoniazid, pyrazinamide and ethambutol.

A CT abdomen was arranged, which showed bilateral pleural effusions, fatty liver and destruction of posterior border of L3 vertebra suggestive of an epidural abscess and consistent with tuberculous infection. The subsequent lumbar spine MRI (figure 2) showed a discitis at L3/4 with an epidural abscess compressing the thecal sac and bilateral paravertebral abscesses.

An urgent neurosurgical opinion was sought; however, as the patient had no neurological deficits, the decision was made for abscess drainage by interventional radiologists, which was done under CT guidance.

The presence of such severe disseminated TB raised the possibility that the patient maybe immunocompromised. However, endocrinological, immunological and virology tests revealed no abnormalities. As the patient had no neurological deficit, and no clinical features of $\mathrm{TB}$ meningitis, the responsible team opted not to perform lumbar puncture.

\section{OUTCOME AND FOLLOW-UP}

The patient was discharged home on anti-mycobacterials for miliary TB after 2 weeks of inpatient treatment. She was to receive anti-mycobacterials for a total of 12 months.

\section{DISCUSSION}

Abdominal pain and weight loss are two of the most common symptoms of abdominal TB worldwide with ascites being one of the most common findings on both examination and abdominal ultrasound. ${ }^{3}$ Our patient manifested all these signs and symptoms. However, one has to bear in mind that these are very non-specific findings and by no means pathognomonic of abdominal TB.

One of the most important findings in our patient was her respiratory symptoms, with an abnormal chest x-ray, which had been missed previously. This is in contrast to other reported cases of abdominal $\mathrm{TB},{ }^{3}{ }^{4}$ in which the majority of patients have been found to be free of pulmonary manifestations with normal chest x-ray and AFB-free sputum.

Focusing on the initial chest x-ray, all attempts to identify who had requested the $\mathrm{x}$-ray had failed as there was no electronic record of the request indicating that it had been requested either at an outpatient clinic or by the patient's general practitioner. It is highly unlikely that the patient would have developed such florid disseminated TB.

The most common recurring theme in the literature is that of the difficulty in diagnosis and several sources con- clude that a high index of clinical suspicion is vital to achieve this. Given the lack of a 'diagnostic gold standard', there is an increasing need for surgical intervention in diagnostic confirmation. 5

The most recent data available from the Health Protection Agency (HPA) ${ }^{2}$ suggests that TB rates are stable; however, these most recent data were published late 2009 using 2008 figures. A very recent study, which looked at TB rates in Europe, disagrees with this HPA data. It suggests that TB rates in the UK, Sweden and Norway are again on the increase most likely due the immigration of people from countries of high incidence. ${ }^{6}$

Looking again at the HPA's annual report on TB surveillance in the UK, there has been a $2.2 \%$ increase in reported cases compared to the previous years with the majority of cases occurring in non-UK born population (77\%). However, although incidence of TB is declining, the rate is stable in the UK-born population. Over half of TB cases reported in 2008 had pulmonary disease with or without any extrapulmonary disease. However, this varied by place of birth: $71 \%$ of UK-born cases had pulmonary TB compared to $48 \%$ of non-UK-born cases. Ten per cent of TB cases involved both a pulmonary and at least one extrapulmonary site. Of the extra-pulmonary sites of disease, the most commonly reported in 2008 were extra-thoracic lymph nodes $(21 \%)$, intra-thoracic lymph nodes (9\%) and the pleura $(7 \%)$, with gastrointestinal tract accounting for $4.7 \%$ of cases only. ${ }^{2}$

These figures highlight the fact that although pulmonary $\mathrm{TB}$ is not an uncommon disease, particularly in the non-UK born population, extra-pulmonary disease is rare and a high index of clinical suspicion is essential for timely diagnosis.

\section{Learning points}

This case highlights the importance of following up young patients with abnormal chest x-ray findings.

- It illustrates the symptoms, signs and extra-pulmonary manifestations of TB infection.

- A high degree of suspicion is required for timely diagnosis of TB in patients in whom the main symptoms are extra-pulmonary.

\section{Competing interests None.}

Patient consent Not obtained.

\section{REFERENCES}

1. http://www.who.int/mediacentre/factsheets/fs104/en/index.html laccessed Mar 2010).

2. Tuberculosis in the UK: Annual Report on Tuberculosis Surveillance in the UK 2009. London: Health Protection Agency Centre for Infections 2009.

3. Uzunkoy A, Harma M, Harma M. Diagnosis of abdominal tuberculosis: experience from 11 cases and review of the literature. World J Gastroenterol 2004;10:3647-9.

4. Ibrahim M, Osoba AO. Abdominal tuberculosis. On-going challenge to gastroenterologists. Saudi Med J 2005;26:274-80.

5. Poyrazoglu OK, Timurkaan M, Yalniz M, et al. Clinical review of 23 patients with tuberculous peritonitis: presenting features and diagnosis. J Dig Dis 2008;9:170-4.

6. Gilbert RL, Antoine D, French CE, et al. The impact of immigration on tuberculosis rates in the United Kingdom compared with other European countries. Int J Tuberc Lung Dis 2009;13:645-51. 


\section{BMJ Case Reports}

This pdf has been created automatically from the final edited text and images.

Copyright 2010 BMJ Publishing Group. All rights reserved. For permission to reuse any of this content visit http://group.bmj.com/group/rights-licensing/permissions.

BMJ Case Report Fellows may re-use this article for personal use and teaching without any further permission.

Please cite this article as follows (you will need to access the article online to obtain the date of publication).

Safavi S, Colaluca B, Sriskandarajah K. Miliary tuberculosis in a young Caucasian adult. BMJ Case Reports 2010;10.1136/bcr.04.2010.2895, date of publication

Become a Fellow of BMJ Case Reports today and you can:

- Submit as many cases as you like

Enjoy fast sympathetic peer review and rapid publication of accepted articles

Access all the published articles

Re-use any of the published material for personal use and teaching without further permission

For information on Institutional Fellowships contact consortiasales@bmjgroup.com

Visit casereports.bmj.com for more articles like this and to become a Fellow 